\title{
Quantitative Determination of Milnacipran by Simple Colorimetric Methods
}

\author{
Md. Mubarakunnisa ${ }^{1}$, Avula Prameela Rani ${ }^{1}$, Seelam Harika ${ }^{1}$, Chandra Bala Sekaran ${ }^{2, *}$ \\ ${ }^{1}$ University College of Pharmaceutical Sciences, Acharya Nagarjuna University, Nagarjuna Nagar, India \\ ${ }^{2}$ Department of Biotechnology, Jagarlamudi Kuppuswamy Choudary College, Guntur, India \\ *Corresponding author: balumphil@gmail.com
}

Received December 23, 2012; Revised January 22, 2013; Accepted February 28, 2013

\begin{abstract}
In the present study, two sensitive, precise and accurate spectrophotometric methods have been developed for the determination of milnacipran in bulk and capsule formulation. The first method is based on the reaction of milnacipran with ninhydrin in $\mathrm{N}, \mathrm{N}^{\prime}$-dimethylformamide medium at $80^{\circ} \mathrm{C}$ temperature to form a colored Ruhemann's purple, which exhibits absorption maximum at $575 \mathrm{~nm}$. The second method is based on extraction of milnacipran into chloroform as ion-pair with bromothymol blue. The yellow colored ion-pair complex exhibits absorption maximum at $410 \mathrm{~nm}$. Beer's law is obeyed in the concentration ranges $2.5-37.5 \mu \mathrm{g} / \mathrm{mL}$ and $2-12 \mu \mathrm{g} / \mathrm{mL}$ of milnacipran for methods I and II, respectively. The effect of experimental variables were investigated and optimized. The validation parameters like linearity, sensitivity, accuracy, precision and robustness were checked by following the ICH guidelines. The proposed methods were applied for the analysis of milnacipran in capsule formulation with good results.
\end{abstract}

Keywords: milnacipran, ninhydrin, bromothymol blue, Ruhemann's purple, ion-pair complex

\section{Introduction}

Milnacipran (MCN) or 1R 2S)-2 aminomethyl-N-Ndimethyl-1-phenyl cyclopropane carboxamine (Figure 1) is an antidepressant, effective in the treatment of fibromyalgia. MCN acts by inhibiting the reuptake of serotonin and nor epinephrine neurotransmitters in 1:3 ratio $[1,2,3]$.

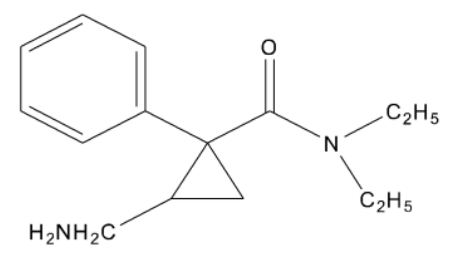

Figure 1. Structure of Milnacipran

The analytical methods reported for the determination of MCN are based on chromatographic techniques. They include RP-HPLC [4,5,6], LC-MS [7], U-HPLC [8] and HPTLC [9]. Most of the reported chromatographic methods have tedious extraction procedures, timeconsuming, complex, multiple sample preparation steps, expensive and requires a skilled person to operate the instrument. Hence these methods are not suitable for routine analysis of MCN in quality control and quality assurance laboratories. Compared with the above mentioned chromatographic methods, spectrophotometry is considered as the most convenient analytical technique in many of the quality control and quality assurance laboratories because of its advantages, such as good selectivity, less expensive, simple instrumentation and less time consuming.

To the best of our knowledge, there are only few reports on the determination of $\mathrm{MCN}$ using spectrophotometric method $[10,11,12,13]$. These methods have drawbacks such as insensitivity, lack of selectivity, use of expensive reagent and rigid control of $\mathrm{pH}$. In the present paper, we report two spectrophotometric methods for the estimation of MCN in bulk and capsules by using ninhydrin and bromothymol blue as analytical reagents.

\section{Materials and Methods}

\subsection{Apparatus}

The absorption spectra and measurements were recorded using a systronics (Schimadzu Corporation, Tokyo, Japan), model visiscan-167, digital spectrophotometer with $1-\mathrm{cm}$ matched quartz cells. Samples were weighed using a schimadzu electronic weighing balance (Schimadzu Corporation, Tokyo, Japan) BL 220H model.

\subsection{Chemicals and Reagents}

All reagents and chemicals were of analytical reagent grade

1. Milnacipran was kindly provided by Matrix laboratories (Hyderabad, India).

2. Milza capsules (Intas pharmaceuticals, Dehradun, India), labeled to contain $50 \mathrm{mg}$ milnacipran/capsule, were purchased from hetero pharmacy (Guntur, India). 
3. Ninhydrin (NHN) was prepared as $2 \%$ solution in N,N'-dimethylformamide (DMF) by dissolving $2 \mathrm{gm}$ of NHN (Merck specialties Pvt. Ltd. Mumbai, India) in 100mL of DMF (Merck specialties Pvt. Ltd. Mumbai, India).

4. Aqueous solution of $0.1 \%$ bromothymol blue (BTB) was prepared by dissolving 100mg of BTB (Thermo Fishers Scientific Pvt. Ltd. Mumbai, India) in $100 \mathrm{~mL}$ of hot water.

5. $1 \mathrm{~N} \mathrm{HCl}$ was prepared by diluting $8.65 \mathrm{~mL}$ of $11.6 \mathrm{~N}$ $\mathrm{HCl}$ to $100 \mathrm{~mL}$ with water.

6. Chloroform (Merck specialties Pvt. Ltd. Mumbai, India) was used for the extraction purpose.

7. Distilled water was used throughout the experiments.

\subsection{Standard Solutions}

An accurately weighed quantity (100mg) of MCN was transferred into a $100 \mathrm{~mL}$ volumetric flask containing $50 \mathrm{ml}$ of water and mixed well. The volume was made upto $100 \mathrm{~mL}$ with water. This stock solution $(1 \mathrm{mg} / \mathrm{mL})$ was further diluted with water to produce working standard solutions of $250 \mu \mathrm{g} / \mathrm{mL}$ (method I) and $100 \mu \mathrm{g} / \mathrm{mL}$ (method II).

\subsection{General Procedure}

\subsubsection{Method I}

Aliquots $(0.1-1.5 \mathrm{~mL})$ of standard solution $(250 \mu \mathrm{g} / \mathrm{mL})$ covering the concentration range of $2.5-37.5 \mu \mathrm{g} / \mathrm{mL}$ for MCN were transferred into a set of $10 \mathrm{~mL}$ boiling test tubes. Then, $1.5 \mathrm{~mL}$ of $2 \% \mathrm{NHN}$ was added to each tube and they were heated in a boiling water bath for 35 minutes at $80^{\circ} \mathrm{C}$. The solutions were cooled, transferred to $10 \mathrm{~mL}$ volumetric flasks and diluted to the mark with distilled water. The absorbance of the resulting solution was measured at $575 \mathrm{~nm}$ against the reagent blank.

\subsubsection{Method II}

Aliquots $(0.2-1.2)$ of standard solution $(100 \mu \mathrm{g} / \mathrm{mL})$ covering the concentration range of $2-12 \mu \mathrm{g} / \mathrm{mL}$ for $\mathrm{MCN}$ were transferred into a set of $125 \mathrm{~mL}$ separating funnels. To each funnel, $1 \mathrm{~mL}$ of $1 \mathrm{~N} \mathrm{HCl}$ and $1 \mathrm{~mL}$ of $0.1 \%$ BTB were added and mixed well. Five $\mathrm{mL}$ of chloroform was added to each separating funnel and shaken vigorously. The funnels were kept aside for 5 mins for the separation of two layers. The colored organic layer was collected in a series of $10 \mathrm{~mL}$ volumetric flasks and made up to the mark with chloroform. The absorbance of organic layer was measured at $410 \mathrm{~nm}$ against the reagent blank.

In both the methods, the calibration curve was plotted with absorbance versus the final concentration of the drug $(\mu \mathrm{g} / \mathrm{mL})$. Alternatively, the corresponding regression equation was derived. The amount of the drug present in the sample solution was computed either from the corresponding calibration curve or from the corresponding regression equation.

\subsubsection{Determination of $\mathrm{MCN}$ in Capsules}

Twenty capsules were emptied, weighed and then mixed well. An accurately weighed quantity of the powder equivalent to $100 \mathrm{mg}$ of MCN was transferred into a small conical flask, extracted successively with $40 \mathrm{~mL}$ of distilled water. The extract was filtered into a $100 \mathrm{~mL}$ volumetric flask and completed to mark with the same solvent. This solution was further diluted with the same solvent as appropriate to obtain the working standard solution of the concentrations $250 \mu \mathrm{g} / \mathrm{mL}$ and $100 \mu \mathrm{g} / \mathrm{mL}$ for methods I and II, respectively. The steps described under "General procedures for method I and method II" were followed. The nominal content of the capsule was determined either from the calibration curve or from the corresponding regression equation.

\section{Results and Discussion}

\subsection{Method I}

Ninhydrin is a widely used chromogenic reagent to quantify compounds with primary amine $[14,15,16,17,18]$. The NHN reacts with the primary amine to produce a colored Ruhemann's purple. The results obtained in the method I is based on the reaction of MCN with NHN in DMF medium via oxidative deamination of the primary amino group of MCN. In DMF medium, NHN is converted to o-carboxyphenylglyoxal which would reduce NHN to 2-hydroxyindan-1,3-dione. The 2-hydroxyindan1,3-dione combines with primary amino group of MCN to form amino derivative. The amino derivative thus produced undergoes condensation with another molecule of NHN to give a colored Ruhemann's purple or diketohydrindylindene-diketohydrindamine, which shows absorption maximum at 575nm (Figure 2). The possible reaction mechanism, based on the reported methods $[14,15,16,17,18]$, is given in Figure 3 .

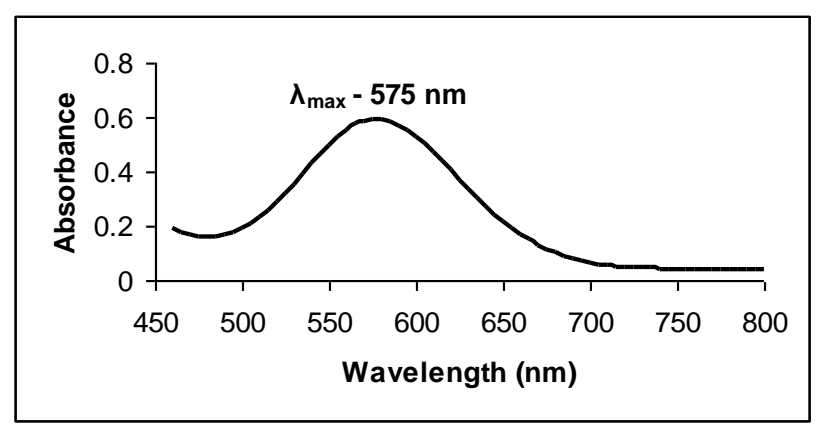

Figure 2. Absorption spectra of Ruhemann's Purple

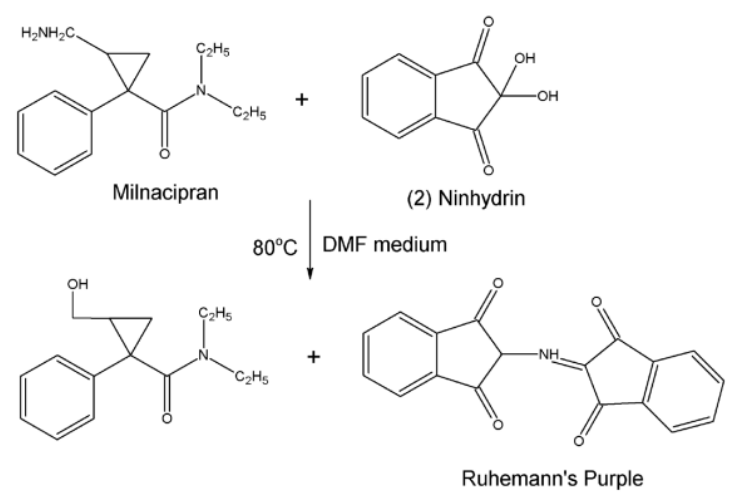

Figure 3. Possible Reaction between MCN and NHN

\subsection{Method II}

Ion-pair complex is formed through the electrostatic interaction between a cation and an anion. The property of 
the compounds possessing basic moieties (primary, secondary or tertiary amino group) to form ion-pair with acidic dyes is suitable for their assay using extractive spectrophotometry. BTB, being an acidic dye is used in the determination of drugs with basic groups [19,20,21,22]. The method II is based on ion-pair complex formation between the MCN and BTB in acidic media. The ion-pair was most likely formed via electrostatic interaction between the most basic center in the MCN (amino group) and the carboxylate anion of the BTB. The MCN-BTB ion-pair complex shows the absorption maximum at $410 \mathrm{~nm}$ against the reagent blank (Figure 4). The possible mechanism of the reaction pathway, based on the reported methods $[19,20,21,22]$, is shown in Figure 5 .

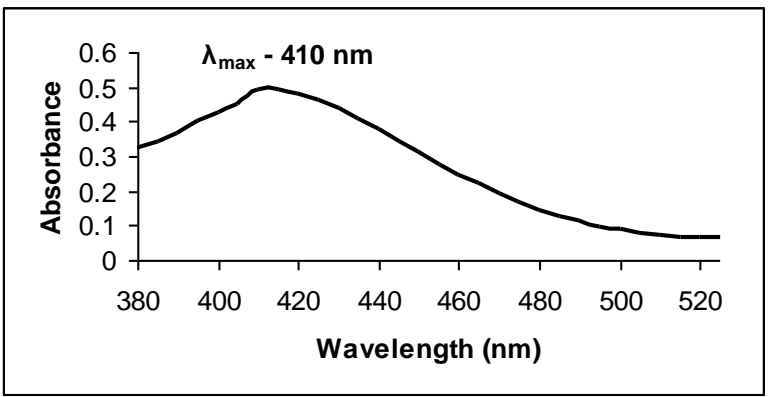

Figure 4. Absorption Spectra of MCN-BTB Ion-Pair Complex<smiles>CCN(CC)C(=O)C1(c2ccccc2)CC1CN</smiles>
$1 \mathrm{~N} \mathrm{HCl}$<smiles>CC1=C(Br)C(O)C(C(C)C)=CC1=C(c1ccccc1S(=O)(=O)[O-])c1cc(C(C)C)c(O)c(Br)c1C</smiles><smiles>Cc1c(C2(c3cc(C(C)C)c(O)c(Br)c3C)OS(=O)(=O)c3ccccc32)cc(C(C)C)c(O)c1Br</smiles>

Bromothymol blue
MCN-BTB Ion-Pair Complex

Figure 5. Possible Reaction between MCN and BTB

\subsection{Optimization of the Experimental Conditions}

\subsubsection{Method I}

Different variables affecting the reaction between the $\mathrm{MCN}$ and NHN, including NHN concentration, temperature and heating time were studied to optimize the reaction conditions to give maximum absorbance. The optimum values of the variables were maintained throughout the experiment.

\subsubsection{Effect of Concentration of NHN}

The influence of the NHN concentration was studied by treating $1 \mathrm{~mL}$ of $\mathrm{MCN}(25 \mu \mathrm{g} / \mathrm{mL})$ with varying volumes $(0.5-2.5 \mathrm{~mL})$ of $2 \% \mathrm{NHN}$ in DMF. It was found that $1.5 \mathrm{~mL}$ of $2 \% \mathrm{NHN}$ reagent solution gives the highest absorbance value as shown in Figure 6. Above this volume, the absorbance decreased. Thus, $1.5 \mathrm{~mL}$ of $2 \%$ NHN in DMF was proved to be sufficient for the determination process.

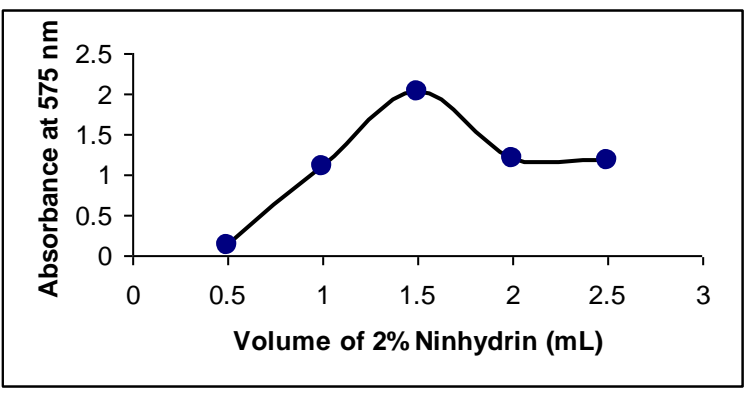

Figure 6. Effect of Concentration of Ninhydrin

\subsubsection{Effect of Temperature}

The influence of the temperature on the rate of formation of the Ruhemann's purple was studied over the temperatures $20^{\circ} \mathrm{C}-80^{\circ} \mathrm{C}$. It is evident from Figure 7 that the maximum absorbance was attained at $80^{\circ} \mathrm{C}$. At higher temperatures $\left(>80^{\circ} \mathrm{C}\right)$ the solution was precipitated. Hence $80^{\circ} \mathrm{C}$ was used as an optimum temperature.

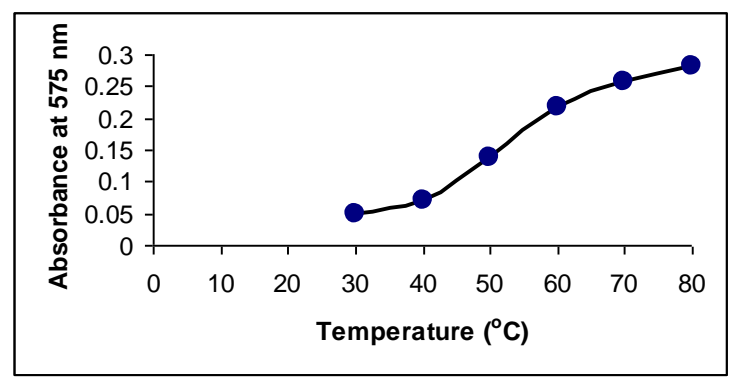

Figure 7. Effect of Temperature

\subsubsection{Effect of Time}

To study the effect of heating time on the formation of the Ruhemann's purple, $1 \mathrm{~mL}$ of $\mathrm{MCN}(25 \mu \mathrm{g} / \mathrm{mL})$ was mixed with $1.5 \mathrm{~mL}$ of $2 \% \mathrm{NHN}$ in DMF. The contents of the mixture were heated upto $20 \mathrm{~min}$ at $80^{\circ} \mathrm{C}$. The results revealed that the maximum intensity of color was obtained at $10 \mathrm{~min}$ of heating and further increase in the heating time did not affect the absorbance intensity (Figure 8). Therefore, the optimum heating time was fixed at $10 \mathrm{~min}$.

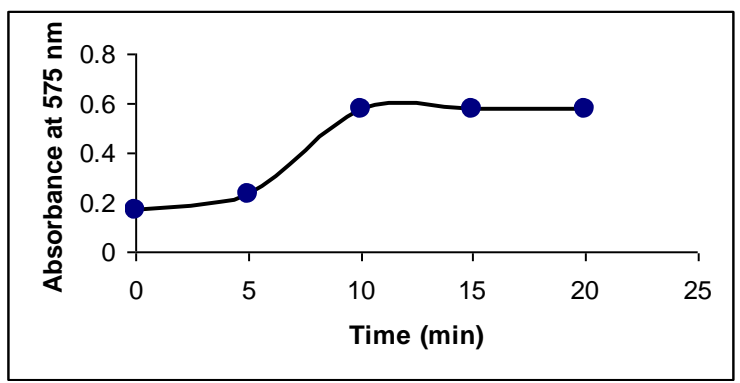

Figure 8. Effect of Time 


\subsubsection{Method II}

\subsubsection{Effect of Concentration of BTB}

The effect of the concentration of BTB in the formation of ion-pair complex was investigated by adding different volumes $(0.2-1.6 \mathrm{~mL})$ of $1.2 \% \mathrm{BTB}$ and $1 \mathrm{~mL}$ of $1 \mathrm{~N} \mathrm{HCl}$ to $1 \mathrm{~mL}$ of $\mathrm{MCN}(10 \mu \mathrm{g} / \mathrm{mL})$. It was found that the maximum absorbance of the yellow color was reached with $1 \mathrm{~mL}$ of $1.2 \% \mathrm{BTB}$, and remained stable with higher volumes (Figure 9). Thus, $1 \mathrm{~mL}$ of $1.2 \%$ BTB was used throughout the experimental investigations.

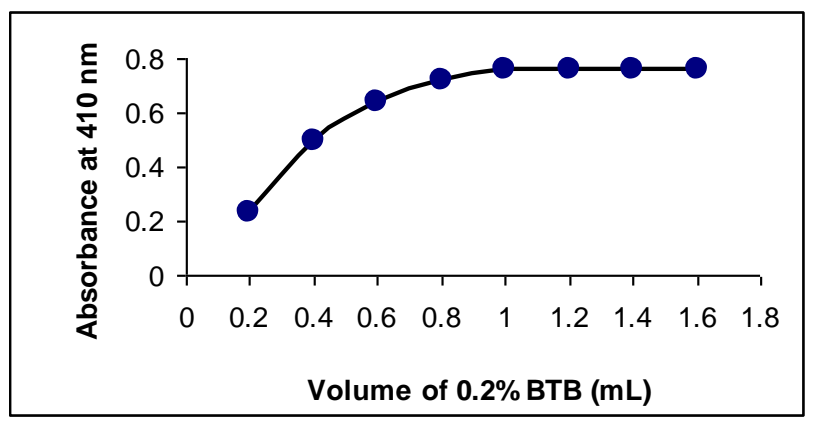

Figure 9. Effect of Concentration of Bromothymol blue

\subsubsection{Effect of Acidity}

The influence of acidity on the development of ion-pair complex was studied by adding $1 \mathrm{~mL}$ of $1.2 \% \mathrm{BTB}$ and different volumes $(0.2-1.6 \mathrm{~mL})$ of $1 \mathrm{~N} \mathrm{HCl}$ to $1 \mathrm{~mL}$ of $\mathrm{MCN}$ $(10 \mu \mathrm{g} / \mathrm{mL})$. The maximum color intensity was observed with $1 \mathrm{~mL}$ of $1 \mathrm{~N} \mathrm{HCl}$, above this volume the absorbance remained constant (Figure 10). Therefore, $1 \mathrm{~mL}$ of $1 \mathrm{~N} \mathrm{HCl}$ was used throughout the experiment.

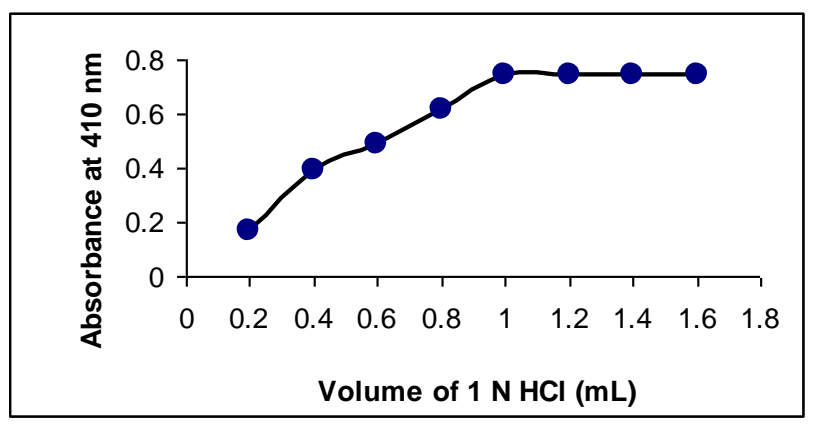

Figure 10. Effect of Acidity

\subsubsection{Effect of Extracting Solvent}

To know the extraction efficiency, different organic solvents (benzene, toluene, carbon tetrachloride and chloroform) were used for the extraction of yellow colored of ion-pair complex. The results are shown in Table 1. Maximum absorbance was obtained while extracted with chloroform. So it is considered to be the good solvent for the extraction.

Table 1. Effect of Extracting Solvent

\begin{tabular}{|c|c|}
\hline \multicolumn{1}{|c|}{ Table 1. Effect of Extracting Solvent } \\
\hline Solvent & Absorbance \\
\hline Chloroform & 0.157 \\
\hline Benzene & 0.123 \\
\hline Carbontetrachloride & No reaction \\
\hline Toluene & No reaction \\
\hline
\end{tabular}

\subsection{Validation of the Developed Methods}

The developed methods were validated by following the ICH guidelines [23]. Different parameters like linearity, sensitivity, precision, accuracy and robustness were checked.

\subsubsection{Linearity}

Linearity was studied in the concentration range from $2.5-37.5 \mu \mathrm{g} / \mathrm{mL}$ and $2-12 \mu \mathrm{g} / \mathrm{mL} \mathrm{MCN}$ for method I and II, respectively. The drug showed good linearity in the tested range. The regression coefficient values for method I and II were found to be $>0.9982$. The results (Table 2) reveal a good and dynamic linearity ranges of the proposed methods.

\subsubsection{Sensitivity}

The sensitivity of the proposed methods was estimated in terms of molar absorptivity, Sandell's sensitivity, limit of quantitation (LOQ) and limit of detection (LOD). The results (Table 2) showed the high sensitivity of the proposed methods.

Table 2. Optical and Regression Characteristics of the Proposed

\begin{tabular}{|c|c|c|}
\hline Methods & Method I & Method II \\
\hline$\lambda_{\max }(\mathrm{nm})$ & 575 & 410 \\
\hline Beer's Limit $(\mu \mathrm{g} / \mathrm{mL})$ & $2.5-37.5$ & $2-12$ \\
\hline Molar Absorbitivity $\left(\mathrm{L} \mathrm{mole}{ }^{-1} \mathrm{~cm}^{-1}\right)$ & $7.692 \times 10^{4}$ & $1.965 \times 10^{5}$ \\
\hline $\begin{array}{c}\text { Sandell's sensitivity } \\
\left(\mu \mathrm{g} \mathrm{cm}^{-2} / 0.001 \text { Absorbance unit) }\right.\end{array}$ & 0.367 & 0.00013 \\
\hline Stability of colored products $(\mathrm{mins})$ & 60 & 30 \\
\hline Regression equation $(\mathrm{Y}=\mathrm{mx}+\mathrm{c})^{\$ \$}$ & & \\
\hline Slope $(\mathrm{m})$ & 0.027 & 0.075 \\
\hline Intercept $(\mathrm{c})$ & 0.01 & 0.0006 \\
\hline Regression coefficient $\left(\mathrm{r}^{2}\right)$ & 0.9982 & 0.9990 \\
\hline LOD $(\mu \mathrm{g} / \mathrm{mL})$ & 0.244 & 0.087 \\
\hline LOQ $(\mu \mathrm{g} / \mathrm{mL})$ & 0.740 & 0.260 \\
\hline
\end{tabular}

$\$ \$ Y=m x+c$, where $\mathrm{Y}$ is the absorbance and $\mathrm{x}$ is the concentration of drug in $\mu \mathrm{g} / \mathrm{mL}$

\subsubsection{Precision and Accuracy}

The precision and accuracy of the proposed methods were established by performing intra-day (repeatability) and inter-day (reproducibility) analyses of three different concentrations $(2.5,20$ and $35 \mu \mathrm{g} / \mathrm{mL}$ - method I; 2,7 and $12 \mu \mathrm{g} / \mathrm{mL}$ - method II), covering the linearity range of MCN, using the proposed methods. The results are reported as standard deviation, relative standard deviation, percentage of error and recoveries in Tables 3 and Table 4. The values are within the acceptable limits, indicating that both the methods have good repeatability and reproducibility.

Table 3. Intra-day Precision and Accuracy

\begin{tabular}{|c|c|c|c|c|c|}
\hline \multirow{2}{*}{ Method } & \multicolumn{2}{|c|}{ Amount of $\mathrm{MCN}(\mu \mathrm{g} / \mathrm{mL})$} & \multirow{2}{*}{$\begin{array}{c}\text { RSD } \\
(\%)\end{array}$} & \multirow{2}{*}{$\begin{array}{c}\text { Recovery } \\
(\%)\end{array}$} & \multirow{2}{*}{$\begin{array}{c}\text { Error } \\
(\%)\end{array}$} \\
\hline & Taken & Found $^{\$} \pm \mathrm{SD}$ & & & \\
\hline \multirow{3}{*}{ I } & 2.5 & $2.504 \pm 0.013$ & 0.519 & 100.16 & 0.16 \\
\hline & 20 & $20.235 \pm 0.163$ & 0.805 & 101.17 & 1.17 \\
\hline & 35 & $35.047 \pm 0.210$ & 0.599 & 100.13 & 0.13 \\
\hline \multirow{3}{*}{ II } & 2 & $2.005 \pm 0.023$ & 1.147 & 100.25 & 0.25 \\
\hline & 7 & $7.007 \pm 0.070$ & 0.999 & 100.10 & 0.10 \\
\hline & 12 & $12.001 \pm 0.135$ & 1.124 & 100.01 & 0.01 \\
\hline
\end{tabular}


Table 4. Inter-day Precision And Accuracy

\begin{tabular}{|c|c|c|c|c|c|}
\hline \multirow{2}{*}{ Method } & \multicolumn{2}{|c|}{ Amount of $\mathrm{MCN}(\mu \mathrm{g} / \mathrm{mL})$} & \multirow{2}{*}{$\begin{array}{c}\mathrm{RSD} \\
(\%)\end{array}$} & \multirow{2}{*}{$\begin{array}{c}\text { Recovery } \\
(\%)\end{array}$} & \multirow{2}{*}{$\begin{array}{c}\text { Error } \\
(\%)\end{array}$} \\
\hline & Taken & Found $^{\$} \pm$ SD & & & \\
\hline \multirow{3}{*}{ I } & 2.5 & $2.501 \pm 0.017$ & 0.679 & 100.04 & 0.04 \\
\hline & 20 & $20.016 \pm 0.177$ & 0.884 & 100.08 & 0.08 \\
\hline & 35 & $34.980 \pm 0.219$ & 0.626 & 99.94 & 0.06 \\
\hline \multirow{3}{*}{ II } & 2 & $2.008 \pm 0.039$ & 1.942 & 100.04 & 0.04 \\
\hline & 7 & $6.99 \pm 0.071$ & 1.015 & 99.85 & 0.15 \\
\hline & 12 & $11.99 \pm 0.035$ & 0.291 & 99.91 & 0.09 \\
\hline
\end{tabular}

${ }^{5}$ Average of three determinations

\subsubsection{Recovery Studies}

The accuracy of the proposed methods was further determined by calculating the recovery of MCN by the method of standard addition. A known amount of MCN at three different levels $(50 \%, 100 \%$ and $150 \%)$ was added to the preanalyzed sample solution and the amount of MCN was estimated by the proposed methods. The results are reported as relative standard deviation and percent recovery in Table 5. The recovery studies showed that there was no interference from excipients in the determination of the MCN by the proposed methods.

Table 5. Results of Recovery Studies by Standard Addition Technique

\begin{tabular}{|c|c|c|c|c|c|}
\hline \multirow[t]{2}{*}{ Method } & \multicolumn{2}{|c|}{$\begin{array}{c}\text { Amount of MCN } \\
(\mathrm{mg})\end{array}$} & \multirow[t]{2}{*}{ Found $^{\$}$} & \multirow{2}{*}{$\begin{array}{c}\text { RSD } \\
(\%)\end{array}$} & \multirow{2}{*}{$\begin{array}{c}\text { Recovery } \\
(\%)\end{array}$} \\
\hline & Tablet & Spiked & & & \\
\hline \multirow{3}{*}{ I } & 50 & 25 & 75.06 & 0.077 & 100.08 \\
\hline & 50 & 50 & 100.06 & 0.112 & 100.06 \\
\hline & 50 & 75 & 125.01 & 0.086 & 100.01 \\
\hline \multirow{3}{*}{ II } & 50 & 25 & 74.98 & 0.285 & 99.97 \\
\hline & 50 & 50 & 99.95 & 0.103 & 99.95 \\
\hline & 50 & 75 & 124.98 & 0.130 & 99.98 \\
\hline
\end{tabular}

\subsubsection{Robustness}

Robustness was performed to check whether the analytical performance of the proposed methods was affected by any small deliberate changes. Robustness of the proposed methods is demonstrated by the determination of the MCN at two different concentrations (within the linearity range) by the proposed methods with minor changes in the experimental variables, such as changing the volume of $2 \%$ NHN \& temperature in method I and changing the volume of $1.2 \%$ BTB \& volume of $1 \mathrm{M} \mathrm{HCl}$ in method II. The relative standard deviation and recovery was calculated each time. The results (Table 6) indicated that the minor changes likely to take place, during the operation of the method did not adversely affect the analytical performance of the proposed methods.

\subsection{Application of the Proposed Methods to Capsule Formulation}

The proposed methods were applied for the determination of $\mathrm{MCN}$ in capsule formulation (Milza capsules, manufactured by Intas pharmaceuticals, Dehradun, India). The results obtained were compared with that of reported UV spectrophotometric method [10]. Paired t-test and F-test (at 95\% confidence level) values were calculated. The results are reported in the Table 7. These results indicate that the proposed and reported methods did not show significant difference with respect to precision and accuracy.
Table 6. Results of Robustness of the Proposed Methods

\begin{tabular}{|c|c|c|c|c|c|}
\hline \multirow[t]{2}{*}{ Method } & \multirow[t]{2}{*}{ Parameter } & \multicolumn{2}{|c|}{$\begin{array}{c}\text { Amount of MCN } \\
(\mu \mathrm{g} / \mathrm{mL})\end{array}$} & \multirow{2}{*}{$\begin{array}{c}\text { RSD } \\
(\%)\end{array}$} & \multirow{2}{*}{$\begin{array}{c}\text { Recovery } \\
(\%)\end{array}$} \\
\hline & & Taken & Found $^{\$}$ & & \\
\hline \multirow{4}{*}{ I } & \multirow{2}{*}{$\begin{array}{l}\text { Temperature } \\
\left(80^{0} \mathrm{C} \pm 2^{0} \mathrm{C}\right)\end{array}$} & 2.5 & 2.52 & 1.23 & 100.80 \\
\hline & & 37.5 & 37.45 & 0.336 & 99.86 \\
\hline & \multirow{2}{*}{$\begin{array}{c}2 \% \mathrm{NHN} \\
(1.5 \mathrm{~mL} \pm 0.2 \\
\mathrm{mL})\end{array}$} & 2.5 & 2.49 & 0.481 & 99.60 \\
\hline & & 37.5 & 37.53 & 0.416 & 100.08 \\
\hline \multirow{4}{*}{ II } & \multirow{2}{*}{$\begin{array}{c}1.2 \% \text { BTB } \\
(1 \pm 0.1 \mathrm{~mL})\end{array}$} & 2 & 2.02 & 1.089 & 101.00 \\
\hline & & 12 & 12.04 & 0.141 & 100.33 \\
\hline & \multirow{2}{*}{$\begin{array}{c}1 \mathrm{~N} \mathrm{HCl} \\
(1.0 \pm 0.1 \mathrm{~mL})\end{array}$} & 2 & 1.99 & 0.603 & 99.50 \\
\hline & & 12 & 11.98 & 0.191 & 99.83 \\
\hline
\end{tabular}

\$Average of three determinations

Table 7. Assay of Milnacipran in Capsules

\begin{tabular}{|c|c|c|c|c|c|c|}
\hline \multirow{2}{*}{ Method } & \multicolumn{2}{|c|}{$\begin{array}{c}\text { Amount of } \\
\text { MCN (mg) }\end{array}$} & \multirow{2}{*}{$\begin{array}{c}\text { RSD } \\
(\%)\end{array}$} & $\begin{array}{c}\text { Recovery } \\
(\%)\end{array}$ & $\begin{array}{c}\text { F- } \\
\text { value }\end{array}$ & $\begin{array}{c}\text { t- } \\
\text { value }\end{array}$ \\
\cline { 2 - 3 } & Tablet & Found $^{\text {S }}$ & & & & \\
\hline I & 50 & 49.98 & 0.172 & 99.96 & 1.36 & 0.212 \\
\hline II & 50 & 49.96 & 0.194 & 99.92 & 0.196 & 0.153 \\
\hline III $^{*}$ & 50 & 49.97 & 0.126 & 99.92 & -- & --- \\
\hline
\end{tabular}

$\$$ Average of five determinations

* Reference method

\section{Conclusion}

The present study deals with the development and validation of two spectrophotometric methods for the determination of MCN using NHN (method I) and BTB (method II) as analytical reagents. The proposed methods offer the advantages of instrumental simplicity and high sensitivity. These methods showed satisfactory accuracy and precision. The results of recovery study proved that the methods are suitable for the determination of MCN in capsule formulations.

\section{Acknowledgement}

The author Md. Mubarakunnisa express her gratitude to the Principal, University College of Pharmaceutical Sciences, Acharya Nagarjuna University, Nagarjuna nagar for her encouragement and support to carry out project work successfully and providing the facilities needed for the work.

\section{Statement of Competing Interests}

The authors do not have any competing interest

\section{List of Abbreviations}

\author{
MCN: Milnacipran \\ NHN: Ninhydrin \\ BTB: Bromothymol blue \\ DMF: N,N'-dimethylformamide
}

\section{References}

[1] Puozzo, C., Panconi, E. and Deprez, D, "Pharmacology and pharmacokinetics of milnacipran," International Clinical Psychopharmacology, 17(Supp 1), S25-35, Jun.2002.

[2] Moret, C., Chaverzon, M., Finberg, J.P. and Briley, M, "Biochemical profile of midalcipran (f2207), 1-Phenyl-1-diethyl- 
aminocarbonyl 2aminomethyl cyclopropane (Z) hydrochloride, a potential fourth generation antidepressant drug," Neuropharmacology, 24(12), 1211-1219, Dec.1985.

[3] Briley, M., Prost, J.F. and Moret, C, "Preclinical pharmacology of milnacipran," International Clinical Psychopharmacology, 11 (Suppl 4), 9-14, Sep.1996.

[4] Vijaya Lakshmi M., Seshagiri Rao, J.V.L.N. and Ravikumar, B.V.N, "Development and validation of RP-HPLC method for the estimation of milnacipran tablet dosage forms," International Journal of Research in Pharmacy and Chemistry, 1(1), 40-43, JanMar. 2011.

[5] Srinivasa Rao, M., Siva Ramakrishna, V., Vardhan, B.V.N. and Ramachandran, D, "A Validated RP-HPLC method for the estimation of milnacipran in tablet dosage forms," International Journal of ChemTech Research, 3(3), 1501-1505, Jul-Sep. 2011.

[6] Priti, J.M. and Deepak, M.K, "Development and validation of RPHPLC method for determination of milnacipran hydrochloride in pharmaceutical formulations," International Journal of Pharmacy and Pharmaceutical Sciences, 2 (Suppl), 137-141, Feb.2010.

[7] Nadège, C. Karine, T., Receveur-Daurel, M., Le-Déodic, M., Lebars, D., Nicholas, M. and Mathieu, M, "Quantification of eight new antidepressants and five of their active metabolites in whole blood by high-performance liquid chromatography-tandem mass spectrometry," Journal of Analytical Toxicology, 31(6), 334-341, Jul-Aug. 2007.

[8] Naresh, T., Shakil, S., Surendranath, R.V., Ravikiran, K. and Suresh, K, "Stability indicating U-HPLC method for milnacipran in bulk drugs and pharmaceutical dosage forms," American Journal of Analytical Chemistry, 3(1), 40-49, Jan. 2012.

[9] Deepak, M.K. and Priti, J.M, "Stability indicating HPTLC method for determination of milnacipran hydrochloride in pharmaceutical formulations," Journal of Planar Chromatography, 24(5), 412418, Oct. 2011.

[10] Punit, B.P., Pragna, K.S., Rakshit, C.P., Bhavesh, S.B. and Arun, $\mathrm{K}$, "Development and validation of UV spectrophotometric method for determination of milnacipran in bulk and pharmaceutical dosage form," Eurasian Journal of Analytical Chemistry, 6(1), 53-58, Jan. 2011.

[11] Sai Praveen, P., Sahiba, M., Rasool, Sk., Srinivasa Rao, T. and Prasad, D, "Spectrophotometric methods for the determination of milnacipran," Asian Journal of Research in Chemistry, 4(1), 114115, Jan. 2011.
[12] Sai Praveen, P., Ramesh, P., Rasool, Sk. and Subramanyam, P, "Spectrophotometric methods for the determination of milnacipran," Journal of Ultra Chemistry, 7(1), Jan. 2001.

[13] Kumar, K.V. and Srivani, V, "Spectrophotometric methods for the determination of milnacipran in the formulation," Research Journal of Pharmacy Technology, 4(8), 1250 -1252, Aug. 2011.

[14] Raza, A., Ansari, T.M. and Rehman, A, "Spectrophotometric determination of lisinopril in pure and pharmaceutical formulations," Journal of Chinese Chemical Society, 52(5), 10551059, Oct. 2005.

[15] Rahman, N. and Azmi, S.N.H, "Spectrophotometric method for the determination of amlodipine besylate with ninhydrin in drug formulations," II Farmaco, 56(10), 731-735, Sep. 2001.

[16] Ansari, T.M., Raza, A. and Rehman, A, "Spectrophotometric Determination of Tranexamic Acid in Pharmaceutical Bulk and Dosage Forms," Analytical Sciences, 21(9), 1133-1135, Sep. 2005.

[17] Abdellatef, H.E. and Khalil, H.M, "Colorimetric determination of gabapentin in pharmaceutical formulation," Journal of Pharmaceutical and Biomedical Analysis, 31(1), 209-214, Feb. 2003.

[18] Elham, A.T. and Nadia, F.Y, Analytical spectrophotometric determination of some drugs for osteoporosis," Chemical and Pharmaceutical Bulletin, 51(12), 1444-1447, Dec. 2003.

[19] Kumar, A.V.V.N.K.S., Saradhi, S.V., Sekaran, C.B. and Reddy, T.V, "Spectrophotometric Analysis of Dutasteride in Pure and Tablet Dosage Forms," Chemical Sciences Journal, CSJ-47, 2012.

[20] Al-Ghannam, S.M, "A simple spectrophotometric method for the determination of $\beta$-blockers in dosage forms," Journal of Pharmaceutical and Biomedical Analysis, 40(1), 151-156, Jan. 2006.

[21] Erk, N, "Extractive spectrophotometric determination of atorvastatin in bulk and pharmaceutical formulations," Analytical Letters, 36 (12), 2699-2711, Oct. 2003.

[22] Cardoso, S.G., Ieggli, C.V.S. and Pomblum, S.C.G, "Spectrophotometric determination of carvedilol in pharmaceutical formulations through charge-transfer and ion-pair complexation reactions," Die Pharmazie, 62(1), 34-37, Jan. 2007.

[23] Validation of Analytical Procedures; Methodology, International Conference on Harmonization (ICH), Text and Methodology Q2(R 1), Complementary Guideline on Methodology dated 06 November 1996, incorporated in November 2005, London. 